\title{
WHY DO PEOPLE ATTEND SPORT EVENTS AT MATURE TOURIST DESTINATIONS? AN ANALYSIS OF VISITORS' MOTIVATION TO ATTEND THE WINDSURF WORLD CUP ON SYLT
}

\author{
THOMAS KÖNECKEl', GRZEGORZ KWIATKOWSKI² \\ ${ }^{1}$ Johannes Gutenberg University Mainz, Faculty of Social Sciences, Media and Sports, \\ Department of Sport Economics, Sport Sociology and Sport History \\ ${ }^{2}$ University of Southern Denmark, Faculty of Business and Social Sciences, \\ Department of Environmental and Business Economics
}

\author{
Mailing address: Grzegorz Kwiatkowski, University of Southern Denmark, 9 Niels Bohrs Street, 6700 Esbjerg, \\ Denmark, tel.: +45 6550 1524, fax: +45 6550 1524, e-mail: gkw@sam.sdu.dk
}

\begin{abstract}
Introduction. Sport events have become a popular tool for the marketing of tourist destinations. In this regard, it has to be kept in mind that the effects events can generate for destinations largely depend on the motivation of the attendees. Building on this insight, the aim of this paper is to compare the motivational structures of two types of visitors (primary purpose event visitors and casual visitors) to the German island of Sylt during a Windsurf World Cup. This event-destination combination was chosen because it represents the tendency for popular tourist resorts to use small-scale sport events in their marketing efforts. Material and methods. The research was conducted using an a priori segmentation of event attendees as casual visitors and primary purpose event visitors that is based on a well-established theoretical background. Results. The results revealed that both visitor groups were mainly motivated by cheering for the surfers and indulging in vicarious achievement. Furthermore, both showed some interest in learning more about the destination. Interestingly, many other motives that had been identified in (sport) tourism research did not seem to be very relevant for the respondents. Conclusion. Event marketers should heavily emphasise the opportunity to watch and closely relate to the surfers. Thus, including internationally popular athletes - if they are also popular in Germany - as well as local heroes in the event seems to be reasonable.
\end{abstract}

Key words: non-mega sport events, destination marketing, fan motivation, leisure motivation, windsurfing

\section{Introduction}

"Events have become an increasingly significant component of destination marketing" [1]. This is so because they can improve the identity and image of a region [2] and can very generally serve as a means of attracting tourists during the on- and off-season [1, 2, 3]. Consequently, many managers see events as "tourism attractions" [2] which can fruitfully be used in their endeavours to promote specific destinations. In this context, it has to be kept in mind that the effects an event generates for a destination largely depend on how it addresses the motivation of potential visitors [1].

In sport event research, two important types of visitors' motives have been discussed that either relate to the motivation to attend the sport event or visit the region where it is staged: fan motives and travel or leisure motives [1, 4, 5, 6, 7]. Understanding these different types of motives is important for destination and sport event managers because "it is useful to differentiate visitors whose primary purpose was to attend the event from those who attend the event but are in town for other reasons" [7]. This is so because their motives for travelling to a specific event destination and attending an event may be quite different from the ones of tourists who are at the destination for another primary purpose [7].

Relating to this reflection by Snelgrove et al., the research project presented here analyses differences in the motive struc- ture of these two visitor groups to further scientific and managerial knowledge on this important topic. We differentiate between primary purpose event visitors, that is people who have come to a region exclusively because of an event, and casual visitors, who have come to a region for other reasons and are visiting an event during such a stay. This means that our a priori segmentation of event attendees as primary purpose and casual visitors has been driven by a well-established theoretical background, and we did not conduct an a posteriori (data-driven) segmentation. The motivational structure of the two groups of event visitors has been captured with an item battery based on a questionnaire by Snelgrove et al. [7], which in turn was assembled building on works by other authors $[1,4,5]$.

The data for the analysis were gathered with a survey held during the 2012 PWA (Professional Windsurfers Association) Windsurf World Cup on the German island of Sylt in the North Sea. The data collection took place on site between $28^{\text {th }}$ September and $7^{\text {th }}$ October. This destination-event combination was chosen because it can be considered a prototypical example of the growing interest of traditional tourist destinations in hosting sport events as tourist attractions and was thus expected to help achieve the main goal of the study, which was to compare the motivational structure of primary purpose and casual (sport) event visitors at a traditional tourist destination.

Since it is well-known on the island when and where the Windsurf World Cup takes place, it was assumed that all the 
spectators present at the event site were there in order to watch the World Cup and not by chance. As the island is a very popular tourist resort and some German states had their fall holidays during the second half of the event in 2012, it could be expected that the event was attended not only by special interest visitors but also by "regular" tourists who opted to see the event as one of the activities during their stay on the island.

Our research project will be presented as follows. In the next section, the literature review and the theoretical background of the study is outlined, focusing on different types of sport event visitors and different types of sport event visitors' motives. The section closes with a short description of the research interest. The following section serves to provide some basic information about the island of Sylt and the PWA Windsurf World Cup traditionally held there. Next, the methodology is outlined by giving information on the data collection and study site as well as relevant parts of the questionnaire. Afterwards, the results of the statistical analysis are presented before the paper finishes with a conclusion.

\section{Literature review and research interest}

As has been mentioned in the introduction, authors who have explored similar issues differentiate between different types of event visitors and have observed some "whose primary purpose was to attend the event [and some] who attend the event but are in town for other reasons" [7]. This differentiation can also be found in research projects regarding the economic impact of events of different sizes (e.g. [8], [9], [10], and [11]). Against this backdrop, Snelgrove et al. [7] identify different motives of spectators at sport events, that is "(1) motives associated with being a fan of the sport [and] (2) motives associated with leisure preferences" ([7]; also see [1], [12], and [13]). It has to be pointed out that some researchers try to differentiate between "motivation" and "motives" (e.g. [14]). But since up to date no widely accepted differentiation has been introduced and "[most] researchers continue to treat the two concepts as one and the same" [15], this study will adhere to this common practice.

Sport fanship and its causes are and have been a very relevant research topic for quite some time (e.g. [5], [6], [7], and $[16])$. Thus, trying to find out what motivates people to become sport fans has led to the development of a number of different instruments to measure fan motivation. Even though "the various scales do not agree on the number of dimensions required to capture fan motivation, nor on which dimensions are the best to use, the various measures share the assumption that fan behaviours and attitudes are driven by fans' motives" ([7]; also see [1], where relevant studies are mentioned). This implies that it is expected "that the higher one's fan motivation, the more likely it is that one will care about and consume sport entertainments" [7].

Consuming sports entertainment does not only include watching sports on TV, following it on the internet, or consulting sports news in print. It obviously also comprises attending events, which can require travelling. Even though the willingness to undertake such travel can be strongly influenced by fan motivation if a person is an avid sport fan, there are other factors that have to be taken into consideration. Logically, this is especially true if somebody is not a sport fan.

Apart from demographics such as age, education, income, gender, or previous attendance, the so-called leisure-related motives are of considerable importance in this regard [1, 7,17$]$.
Similar to fan motivation, leisure motivation has been analysed using multidimensional instruments. Beard and Ragheb (1983) developed the Leisure Motivation Scale measuring four dimensions of leisure motivation: the social, escape, learning, and mastery dimensions. Since travel-related motives "can be effectively modelled using Beard and Ragheb's dimensions of leisure motivation" ([1]; also see [7]), they served as a foundation for the respective part of the questionnaire that was used in the project described here.

It has to be mentioned that there are a number of other studies pertaining to sport event visitors' or (sport) tourists' motivation both in tourism- and event-related literature (e.g. [18], [19], and [20]). Yet, in contrast to existing contributions, the current study targets an issue that is of great academic and managerial importance and has not yet been scrutinised: it is our goal to compare the motivational structure of primary purpose and casual (sport) event visitors at a traditional tourist destination. Since a growing interest in hosting sport events can be observed in many traditional tourist destinations worldwide [21, $22,23,24]$, this analysis should be beneficial for sport, event, and destination mangers as well as researchers in these fields.

\section{Material and methods}

\section{Data collection and study site}

The island of Sylt is situated in the very north of Germany in the North Sea, close to the border with Denmark. The island has only about 20,000 inhabitants but over 58,000 guest beds in hotels and tourist apartments. The very strong tourism demand manifests itself in approximately 850,000 visitors per year who account for some 6 million overnight stays. The island is an established, rather high-priced tourist destination. Yet, it is not easily accessible because there are no bridges or tunnels that can be used by cars. Tourists usually get there by train, by ferry, or by plane.

The PWA Windsurf World Cup has been staged on Sylt annually since 1984. Over the years, it has become the largest and most important (regular) windsurfing event in the world, usually attracting at least 200,000 spectators over a period of ten days (including double-counting for visits on more than one day). Thus, it is considered one of the most prominent PWA Tour events, if not the most prominent one [25, 26, 27].

The primary data for this study were collected during the PWA Windsurf World Cup 2012. The event was held between $28^{\text {th }}$ September and $7^{\text {th }}$ October, 2012, in the capital and largest town of Sylt called Westerland. This town accounts for approximately half of the overnight stays on the island [28].

The event-destination combination provides an interesting case for a number of reasons. On the one hand, Sylt is a very attractive tourist destination characterised by strong tourism demand. On the other hand, the PWA Windsurf World Cup is one of the most prominent PWA World Tour events worldwide and has been held on the island since 1984. On top of that, part of the hosting period coincided with the fall holidays in several German states in 2012. Due to these factors, it could be expected that, aside from special-interest tourists who had come to the island exclusively for the event (primary purpose event visitors), there would be a significant group of ordinary leisure travellers present. Thus, the survey conducted at the event site was expected to provide a solid empirical basis for a comparison between both groups. This is even more so because the number of event visitors is very high in comparison to the total population of the island: 200,000 spectators compared to only about 
20,000 inhabitants. Consequently, it was assumed that only a relatively small number of local residents would attend the event compared to the number of tourists.

The data were collected by means of a self-administered paper-based questionnaire, described in the section below. The team of interviewers consisted of ten graduate students and two $\mathrm{PhD}$ students. In a preceding meeting, the interviewers were instructed regarding the purpose, scope, target group, and technique of the data collection. The data collection took place exclusively on the waterfront promenade where the competition was held. Because the entire population of event attendees was unknown, random cluster sampling was used to collect the necessary data [29]. Furthermore, to provide the best possible sample representation, the interviews were conducted during all event days. The information that the survey had a purely scientific character was given to the spectators as an incentive for participation.

It has to be mentioned that the entrance to the promenade was not free of charge, as there is a visitors' tax in this part of the shore on Sylt. Access to the event site was not charged extra, but because the site was restricted to a clearly marked zone at the end of the promenade, it could be expected that no casual passers-by would be encountered. Thus, it can be assumed that only people with a particular interest in windsurfing competitions or in some of the multiple forms of non-sport attractions (music, food, equipment presentations, etc.) were interviewed.

Due to the international nature of the event (it was a world cup) and the fact that it was staged very close to the Danish border, two versions of the questionnaire were offered to the participants: depending on their language preferences, they could choose between a German and English one. Thus, no potential participants seem to have been excluded because of language problems.

\section{Questionnaire}

The questionnaire used in the survey collected data on the following: (a) trip-related characteristics (origin of the interviewee, previous attendance, planning horizon, composition of immediate group, mode of transport, accommodation, and length of and motivation for stay), (b) consumption patterns (expenditure patterns), (c) behavioural characteristics (leisure and fan motivation), and (d) socio-demographic information (age, gender, education, employment status, household status, and income). Both the German and English versions of the questionnaire had been tested prior to the survey to identify and eliminate potential shortcomings.

This research project was not the only one for which data were collected using the questionnaire. However, below we will only discuss the parts of the questionnaire that are relevant for this project.

\section{Questions differentiating the spectator groups}

Primary purpose event visitors and casual visitors were differentiated with a single question related to similar questions in previous surveys (e.g. [7], [9], [10], [11], and [30]). The question was "Did you come to Sylt ONLY because of the Reno Windsurf World Cup?" (Reno was the name sponsor that year). If the respondents checked "yes", they were considered primary purpose event visitors, since they had come to Sylt exclusively because of the windsurf event. If they checked "no", they were considered casual visitors. Residents and non-respondents to this question were excluded from further analysis.

Questions regarding fan motivation and leisure motivation

Like in the questionnaire developed by Snelgrove et al., "[t]wo forms of motivation were assessed: leisure motivation and fan motivation" [7]. Their questionnaire was deemed a solid methodological basis for this study as its items were assembled building on works by several other authors $[1,4,5]$ and have proven to be suitable for empirical work in sport event research. Due to this, almost all corresponding items were utilised in the survey. As can be seen in the following description, only one item was altered, and one additional item was included.

Leisure motivation was measured using three of the four dimensions of the Leisure Motivation Scale developed by Beard and Ragheb [4] (tab. 1). Following the reflections by Snelgrove

Table 1. List of dimensions and items used in the survey

One of the reasons for attending the Reno Windsurf World Cup is...

Leisure motivation

Learning more about destination

... to expand my knowledge about Sylt.

... to discover new things about Sylt.

... to satisfy my curiosity about Sylt.

Learning more about windsurfing

... to satisfy my curiosity about windsurfing.

... to discover new things about windsurfing.

... to expand my knowledge about windsurfing.

Escape

... to get away from my everyday life.

... to relax physically.

... to relax mentally.

\section{Socialisation}

... to build friendships with others.

... to interact with others.

... to meet new and different people.

\section{Fan motivation}

Entertainment experience

... to watch high level windsurfing.

... to be part of a major windsurfing event.

the main reason I watch windsurfing is to cheer for my favourite surfers.

I like being part of the festivities surrounding the Reno Windsurf World Cup.

... I like the stimulation I get from watching windsurfing.

\section{Aesthetics}

... there is a certain natural beauty to windsurfing.

... I enjoy watching windsurfing because to me it is a form of art.

Vicarious achievement

When my country or my favourite surfer wins, I feel my status as a fan is enhanced.

I feel a sense of accomplishment when my country or my favourite surfer wins. 
et al. [7] and Kim and Chalip [1], items relating to the mastery motive were omitted, "as it was deemed unlikely that spectators would expect to develop mastery [in the sport] by merely watching the event" ([7] relating to [1]). Consequently, items representing three dimensions of leisure motivation were included in the questionnaire, that is the learning, escape, and social dimensions, shown in table 1 . The learning motivation was subdivided, therefore " $\mathrm{t}$ ]wo types of learning motives were assessed: learning about the destination and learning about [windsurfing]", and "the four dimensions were measured via three items each" [7]. Fan motivation was subdivided into three dimensions: entertainment experience, aesthetics, and vicarious achievement. Entertainment experience was measured with a total of five items, two of which were originally developed by Kim and Chalip [1]. The third item in the survey carried out by Snelgrove et al. [7] at the Pan American Youth Athletics Championships was geared towards youth athletes ("to see future stars of Athletics"). Since this was not applicable to a world cup, it was changed to "the main reason I watch windsurfing is to cheer for my favourite surfers". The remaining two items related to entertainment experience had originally been developed by Wann [5]. The same is true of the items relating to aesthetics and vicarious achievement (two items each).

Acknowledging the arguments for and against the various forms of the Likert scale [31], the current study used an even number (6-point) of ratings in the scale, following Snelgrove et al. [7]. All items had to be ranked on this six-point scale, after the following instruction was given: "Spectators have many reasons for attending the Reno Windsurf World Cup. Please rate how important each reason is to you, using the following scale". The scale read as follows: "strongly disagree - disagree - slightly disagree - slightly agree - agree - strongly agree". During the analysis of the data, numerical values between 1 for "strongly disagree" and 6 for "strongly agree" were assigned to the answers. To calculate the aggregate measure for each of the four dimensions, all valid answers to a specific subscale "were averaged to form an aggregate measure" [7].

\section{Results}

\section{Summary statistics}

Overall, 946 questionnaires were collected from respondents who almost exclusively resided in Germany (98\%). A total of $893(94.4 \%)$ of the questionnaires were filled in by the target group of non-resident spectators. Assuming a population size of 200,000 attendees and a confidence level of 95\%, the margin error of the collected sample is $3.27 \%$, which is acceptable according to the existing literature [32]. Thus, a satisfactory sample size was achieved.

Both visitor groups were represented with data sets of considerable size (364 for the primary purpose event visitors and 516 for the casual visitors). As can be seen in columns 3, 4, and 5 of table 2 , several statistically significant differences could be found between the two event visitor groups. With regard to socio-demographic characteristics, differences in age, gender, and household status were found to be significant. Furthermore, differences in all travel-related characteristics showed statistical significance. Yet, as will be discussed below, not all of these differences seem to be relevant.

Regarding socio-demographics, it can be questioned if the four-and-a-half-year age difference between the two groups is very relevant as far as living, spending, holiday habits, and other factors are concerned. However, a look at the household status reveals that more of the primary purpose visitors lived alone (an additional 17\%), whereas more of the casual visitors were either married or lived with a partner (a difference of over 15\%). Strikingly, only $27 \%$ and $28 \%$ of respondents from the two groups, respectively, had children (either as single parent or as a couple). Thus, both groups were very similar insofar as almost three quarters had no children. This is in line with the observation made during the survey that more female than male spectators were present at the Windsurf World Cup. Consequently, it is not astonishing that both groups mainly consisted of female interviewees. Yet, since $68.5 \%$ of the primary purpose and "only" $58.6 \%$ of the casual visitors were female, the $10 \%$ difference in group composition was highly significant. Finally, it has to be mentioned that there were no statistically significant differences in the level of education or the household income.

Looking at trip-related characteristics, the primary purpose visitors' additional expenditure per day and person $(56.23 \mathrm{com}-$ pared to 52.86 euros) amounted to approximately $6 \%$ and was not significant. Regarding the length of stay, the casual visitors surpassed the other group by a statistically significant 1.4 days ( 7 compared to 5.6). Both groups mainly consisted of repeat visitors, and almost three quarters of all primary purpose respondents fell into that category. This was also true of almost $60 \%$ of the casual visitors. The accommodation categories that had to be paid for (rented holiday apartment, hotel, bed and breakfast, as well as camping and related accommodation) were very similar, rented apartments having been chosen by almost two thirds of respondents in both groups. The only larger difference was that almost $11 \%$ of the special interest tourists but only about $6 \%$ of the casual tourists commuted from their regular homes. The average travel time to the island amounted to almost six hours and over seven hours for primary purpose and casual visitors, respectively. The difference was highly significant. The composition of the different respondent groups somewhat mirrored the household status and also showed highly significant differences. Over $60 \%$ of the primary purpose group travelled with friends and almost 24\% with their family, whereas slightly fewer than $50 \%$ of the casual visitors were with their family and over 39\% with friends. The percentages of people travelling alone (between $4 \%$ and $6 \%$ ) or with friends and family (approximately $8 \%$ ) were almost alike.

To sum up, it can be stated that both groups spent almost one week on the island. Both planned their trips well ahead and travelled several hours to get to Sylt, where most of the spectators had been before. Average spending amounted to about 55 euros per day, and almost $90 \%$ of the respondents claimed to have paid for their accommodation. Members of both groups mostly travelled with friends or family, and only very few travelled with either both or neither one of these. The age difference did not seem to be very large, with both groups averaging around 40 years of age. Educational and income levels were about the same. Furthermore, both groups mainly consisted of females, who were even more numerous in the primary purpose group.

\section{Leisure motivation and fan motivation}

For the sake of better legibility, the presentation of the analysis of leisure and fan motivation has been split into two parts. In the first part, the aggregated motivational dimensions will be presented to give a general overview of the results (tab. 3). Afterwards, aggregated results for all items will be presented in table 4 , and the striking ones will be explicitly addressed in the text.

As laid out before, the different values of leisure motivation and fan motivation were computed by assigning numerical values between 1 for "strongly disagree" and 6 for "strongly agree" to the answers of each respondent for each of the items. Thus, the 
Table 2. Description of variables and summary statistics

\begin{tabular}{|c|c|c|c|c|}
\hline Variable & Description & $\begin{array}{c}\text { Primary } \\
\text { purpose event visitors }\end{array}$ & $\begin{array}{l}\text { Casual event } \\
\text { visitors }\end{array}$ & $\begin{array}{l}\text { Wilcoxon-Mann- } \\
\text { Whitney or } \mathrm{X}^{2} \text { test }\end{array}$ \\
\hline \multicolumn{5}{|c|}{ Socio-demographic characteristics } \\
\hline Age & Age of individual (mean in years) & $37.00(n=349)$ & $41.67(n=499)$ & $z=-4.573^{* *}$ \\
\hline Gender & $\begin{array}{l}\text { Gender of individual (in \%) } \\
\text { Female } \\
\text { Male } \\
\end{array}$ & $\begin{array}{l}68.48(n=239) \\
31.52(n=110)\end{array}$ & $\begin{array}{l}58.63(n=292) \\
41.37(n=206)\end{array}$ & $x^{2}=5.772^{* *}$ \\
\hline Education & $\begin{array}{l}\text { Education of individual (in \%) } \\
\text { Lower secondary school } \\
\text { Upper secondary school } \\
\text { Undergraduate and postgraduate (Bachelor's, Master's, or other } \\
\text { diploma) } \\
\text { Doctoral degree }\end{array}$ & $\begin{array}{c}31.43(n=110) \\
30.29(n=106) \\
35.14(n=123) \\
3.14(n=11)\end{array}$ & $\begin{array}{c}30.66(n=153) \\
25.25(n=126) \\
40.48(n=202) \\
3.61(n=18)\end{array}$ & $x^{2}=2.415$ \\
\hline Household status & $\begin{array}{l}\text { Household status of individual (in \%) } \\
\text { Single without children } \\
\text { Married/partner without children } \\
\text { Single with children } \\
\text { Married/partner with children } \\
\end{array}$ & $\begin{array}{c}47.37(n=162) \\
26.02(n=89) \\
4.09(n=14) \\
22.51(n=77)\end{array}$ & $\begin{array}{c}30.51(n=151) \\
41.21(n=204) \\
3.23(n=16) \\
25.05(n=124)\end{array}$ & $x^{2}=24.544^{* *}$ \\
\hline Income & $\begin{array}{l}\text { Household income of individual per month, before tax (in EUR) } \\
\text { Low-income } \quad 0-3,300 \\
\text { Mid-income } 3,300-5,500 \\
\text { High-income } 5,500+ \\
\end{array}$ & $\begin{array}{c}30.77(n=92) \\
38.13(n=114) \\
31.10(n=93) \\
\end{array}$ & $\begin{array}{l}25.41(n=109) \\
40.33(n=173) \\
34.27(n=147)\end{array}$ & $x^{2}=3.235$ \\
\hline \multicolumn{5}{|c|}{ Trip-related characteristics } \\
\hline Expenditures & $\begin{array}{l}\text { Spending per day and capita; costs of accommodation and } \\
\text { transport excluded (mean in EUR) }\end{array}$ & $56.23(n=229)$ & $52.86(n=319)$ & $z=1.183$ \\
\hline Length of stay & Duration of stay on the island (mean in days) & $5.62(n=324)$ & $7.02(n=448)$ & $z=-4.831^{* *}$ \\
\hline Planning in advance & Number of days that the trip was planned ahead (mean in days) & $165.44(n=320)$ & $121.19(n=430)$ & $z=4.600^{* *}$ \\
\hline Repeat visitor & $\begin{array}{l}\text { Repeat visitor (in \%) } \\
\text { Yes } \\
\text { No } \\
\end{array}$ & $\begin{array}{c}72.84(n=236) \\
27.16(n=88)\end{array}$ & $\begin{array}{l}59.38(266) \\
40.63(182) \\
\end{array}$ & $x^{2}=14.988^{* *}$ \\
\hline Accommodation & $\begin{array}{l}\text { Type of accommodation chosen (in \%) } \\
\text { At home (day visitors) } \\
\text { Rented holiday apartment } \\
\text { Hotel or bed and breakfast } \\
\text { Friends, summer house, or camping } \\
\end{array}$ & $\begin{array}{c}10.93(n=33) \\
64.57(n=195) \\
12.91(n=39) \\
11.59(n=35)\end{array}$ & $\begin{array}{c}5.90(n=25) \\
65.09(n=276) \\
16.04(n=68) \\
12.97(n=55)\end{array}$ & $x^{2}=7.034^{n}$ \\
\hline Travel time & $\begin{array}{l}\text { Continuous variable, the average journey time (in minutes) } \\
\text { from a given postal code area to Westerland. To generate travel } \\
\text { time, a two-step procedure was applied. First, based on postal } \\
\text { code information, a centroid of a given postal code area was } \\
\text { defined. Second, route planning software (MapPoint) was utilised } \\
\text { to estimate the journey time from a given postal code area to } \\
\text { Westerland. For methodological reasons, the estimation was } \\
\text { restricted to German citizens, since } 98 \% \text { of the respondents } \\
\text { lived in Germany and only } 2 \% \text { in other countries. Thus, it was not } \\
\text { considered fruitful to go to great lengths to estimate their travel } \\
\text { times as well. }\end{array}$ & $352.85(n=295)$ & $431.49(n=417)$ & $z=-4.654^{* *}$ \\
\hline $\begin{array}{l}\text { Composition of } \\
\text { immediate group }\end{array}$ & $\begin{array}{l}\text { Composition of immediate group (in \%) } \\
\text { Alone } \\
\text { Family } \\
\text { Friends } \\
\text { Friends and family } \\
\end{array}$ & $\begin{array}{c}5.96(n=19) \\
23.51(n=75) \\
62.07(n=198) \\
8.46(n=27)\end{array}$ & $\begin{array}{c}4.29(n=18) \\
48.81(n=205) \\
39.05(n=164) \\
7.86(n=33)\end{array}$ & $x^{2}=51.332^{\star *}$ \\
\hline
\end{tabular}

mean value for all items is 3.5. To obtain the aggregate measure for each dimension, an average of the relevant item values was calculated, and the mean value for each dimension was 3.5 as well. The Wilcoxon-Mann-Whitney test was used to determine statistically significant differences between the two groups. The results are presented in table 3 .

The fan motivation of the primary purpose event visitors was higher than their leisure motivation. The same is true of 
Table 3. Average scores of the two visitor groups for the motivation dimensions

\begin{tabular}{|c|c|c|c|c|}
\hline Variables & $\begin{array}{c}\text { Primary } \\
\text { purpose } \\
\text { event } \\
\text { visitors }\end{array}$ & $\begin{array}{l}\text { Casual } \\
\text { event } \\
\text { visitors }\end{array}$ & Differences & $\begin{array}{l}\text { Wilcoxon- } \\
\text { Mann- } \\
\text { Whitney } \\
\text { test }\end{array}$ \\
\hline $\begin{array}{l}\text { Leisure } \\
\text { motivation }\end{array}$ & 2.95 & 3.40 & -0.45 & $z=-3.655^{\star *}$ \\
\hline $\begin{array}{l}\text { Learning more } \\
\text { about destination }\end{array}$ & $\underline{3.52}$ & $\underline{3.78}$ & -0.26 & $z=-2.173^{*}$ \\
\hline $\begin{array}{l}\text { Learning } \\
\text { more about } \\
\text { windsurfing }\end{array}$ & 3.06 & $\underline{3.65}$ & -0.59 & $z=-0.909$ \\
\hline Escape & 2.52 & 2.64 & -0.12 & $z=-0.909$ \\
\hline Socialisation & 2.69 & $\underline{3.52}$ & -0.84 & $z=-7.425^{* *}$ \\
\hline $\begin{array}{c}\text { Fan } \\
\text { motivation }\end{array}$ & 3.18 & $\underline{3.84}$ & -0.66 & $z=-6.844^{* *}$ \\
\hline $\begin{array}{c}\text { Entertainment } \\
\text { experience }\end{array}$ & 3.02 & $\underline{3.91}$ & -0.88 & $z=-9.446^{* *}$ \\
\hline Aesthetics & 2.63 & 3.16 & -0.54 & $z=-4.986^{* *}$ \\
\hline $\begin{array}{c}\text { Vicarious } \\
\text { achievement }\end{array}$ & $\underline{3.88}$ & $\underline{4.45}$ & -0.57 & $z=-4.452^{* *}$ \\
\hline Differences & -0.23 & -0.44 & & \\
\hline
\end{tabular}

Notes: ${ }^{* *} \mathrm{p}<0.01,{ }^{*} \mathrm{p}<0.05$. Values above the mean-value of 3.5 are underlined.

the casual visitors by an even larger margin, with a difference of 0.44 as compared to 0.23 for the primary purpose group. As can be seen in table 3 , both aggregated motivations are much higher for the casual visitors. They amount to 3.4 (leisure) and 3.84 (fan motivation), respectively. The only aggregated motivation that scored above average (higher than 3.5) was the casual tourists' fan motivation. The scores for the primary purpose visitors were computed with 2.95 for leisure and 3.18 for fan motivation. This means that the leisure as well as fan motivation of the respondents from this group were far below the average value of 3.5.

A look at the different dimensions of the two motivations shows that only two of the seven motives of the primary purpose visitors scored average values over 3.5: "learning more about the destination" and "vicarious achievement". This means that this group seems to have been mainly motivated by these two dimensions.

Contrarily, five motives of the casual visitors scored above average. As can be seen in table 3, only escape and aesthetics are - well - below 3.5. Vicarious achievement has the highest average value (4.45), indicating that the respondents greatly profited from seeing the surfers perform well.

A more detailed analysis of the average values of the different items points in the same direction. As can be seen in table 4 , the average item values in the different dimensions usually do not vary greatly. The only major exception is the fan motivation dimension "entertainment experience". For both groups, the items "to watch high level windsurfing" and "I like being part of the festivities surrounding the Reno Windsurf World Cup" scored rather low if compared to the average values of the dimension. Contrarily, "the main reason I watch windsurfing is to cheer for my favourite surfers" turned out to be the most relevant of all items in the survey for both visitor groups alike.
Table 4. Average scores of the two visitor groups for particular items of the motivation dimensions

\begin{tabular}{|c|c|c|}
\hline $\begin{array}{l}\text { One of the reasons for attending the } \\
\text { Reno Windsurf World Cup is... }\end{array}$ & $\begin{array}{c}\text { Primary } \\
\text { purpose } \\
\text { event visitors }\end{array}$ & $\begin{array}{l}\text { Casual event } \\
\text { visitors }\end{array}$ \\
\hline Leisure motivation & 2.95 & 3.40 \\
\hline Learning more about destination & 3.52 & 3.78 \\
\hline ... to expand my knowledge about Sylt. & $\underline{3.74}$ & $\underline{4.02}$ \\
\hline ... to discover new things about Sylt. & 3.38 & 3.54 \\
\hline ... to satisfy my curiosity about Sylt. & 3.45 & 3.78 \\
\hline Learning more about windsurfing & 3.06 & 3.65 \\
\hline ... to satisfy my curiosity about windsurfing. & 2.87 & 3.57 \\
\hline $\begin{array}{l}\text {... to discover new things about } \\
\text { windsurfing. }\end{array}$ & 3.09 & 3.60 \\
\hline $\begin{array}{l}\ldots \text { to expand my knowledge about } \\
\text { windsurfing. }\end{array}$ & 3.21 & 3.77 \\
\hline Escape & 2.52 & 2.64 \\
\hline ... to get away from my everyday life. & 2.26 & 2.84 \\
\hline ... to relax physically. & 2.71 & 2.57 \\
\hline ... to relax mentally. & 2.59 & 2.50 \\
\hline Socialisation & 2.69 & 3.52 \\
\hline ... to build friendships with others. & 2.91 & 3.80 \\
\hline ... to interact with others. & 2.68 & 3.54 \\
\hline ... to meet new and different people. & 2.47 & 3.23 \\
\hline Fan motivation & 3.18 & 3.84 \\
\hline Entertainment experience & 3.02 & 3.91 \\
\hline ... to watch high level windsurfing. & $\underline{2.50}$ & $\underline{3.11}$ \\
\hline ... to be part of a major windsurfing event. & 2.66 & 3.97 \\
\hline $\begin{array}{c}\text {... the main reason I watch windsurfing is } \\
\text { to cheer for my favourite surfers. }\end{array}$ & $\underline{4.22}$ & $\underline{4.99}$ \\
\hline $\begin{array}{l}\text {... I like being part of the festivities } \\
\text { surrounding the Reno Windsurf World } \\
\text { Cup. }\end{array}$ & $\underline{2.33}$ & $\underline{3.43}$ \\
\hline $\begin{array}{l}\text {... I like the stimulation I get from watching } \\
\text { windsurfing. }\end{array}$ & 3.40 & 4.03 \\
\hline Aesthetics & 2.63 & 3.16 \\
\hline $\begin{array}{l}\text {... there is a certain natural beauty to } \\
\text { windsurfing. }\end{array}$ & 2.43 & 2.83 \\
\hline $\begin{array}{l}\ldots \text { I enjoy watching windsurfing because to } \\
\text { me it is a form of art. }\end{array}$ & 2.82 & 3.49 \\
\hline Vicarious achievement & 3.88 & 4.45 \\
\hline $\begin{array}{l}\text {... when my country or my favourite } \\
\text { surfer wins, I feel my status as a fan is } \\
\text { enhanced. }\end{array}$ & 3.96 & 4.61 \\
\hline $\begin{array}{c}\ldots \text { I feel a sense of accomplishment when } \\
\text { my country or my favourite surfer wins. }\end{array}$ & 3.80 & 4.29 \\
\hline
\end{tabular}

Notes: Underlined values are discussed in the text. 
Since this item had been altered from the original questionnaire by Snelgrove et al. [7], another calculation was conducted for "entertainment experience" omitting this item. It turned out that for both visitor groups, the average value for this dimension dropped by approximately 0.3 . This means that "vicarious achievement" became even more prominent as the most relevant dimension.

Against this backdrop, two more observations have to be pointed out regarding the different items of the "entertainment experience" dimension. Firstly, "to watch high level windsurfing" was scored comparably low by both groups (2.5 and 3.11). Secondly, the primary purpose visitors in particular did not seem to be very fond of "being part of the festivities surrounding the Reno Windsurf World Cup" and scored this item with a mere 2.33 .

Regarding the item-by-item analysis, one last result stands out. The item "to expand my knowledge about Sylt" scored rather high in both visitor groups. For the primary purpose visitors, it was only surpassed by the item relating directly to the athletes ("cheer for my favourite surfers") as well as the "vicarious achievement" dimension. Almost the same is true for the casual visitors, who furthermore scored the "stimulation I get from windsurfing" as slightly more important.

\section{Conclusion}

In the introduction, it has been pointed out that "[e]vents have become an increasingly significant component of destination marketing" [1]. In the case of the PWA Windsurf World Cup on the island of Sylt, which regularly attracts over 200,000 spectators over a ten-day period, this marketing effort seems to be successful, since many come to the island exclusively because of the event (primary purpose event visitors) and stay for an average 5.6 nights. When evaluating this figure, it has to be taken into account that the event does not take place in the high season, which is during the summer.

As the survey showed, primary purpose visitors were largely motivated by the vicarious achievement dimension as well as the opportunity to support their favourite surfers, which is rather intuitive. Surprisingly, the calculations for the other dimensions of fan motivation yielded scores well below the average value of 3.5. This can be considered an indication of the dominance of the vicarious achievement construct among primary purpose visitors. Popular competitors seem to be more important than a high-level competition. Yet, it has to be kept in mind that windsurfing competitions are highly dependent on the weather, and bad weather can prevent a highly attractive competition. A knowledgeable audience might take this into consideration when planning to attend an event and might manage their expectations accordingly.

For the marketing of the event, this observation implies that it should heavily emphasise the opportunity to watch and closely relate to the surfers. Thus, including internationally popular athletes - if they are also popular in Germany - as well as local heroes in the event communication seems to be reasonable. It is worth noting that only very few respondents were not residents of Germany ( $2 \%)$, which is why the country has to be considered the major target market.

If other target markets are to be addressed, an adaptation of this strategy could be applicable. Since Scott [33] shows that specific festivals (and this should be true here as well) attract people of a certain kind, the dominant importance of the opportunity to bask in the reflected glory of popular surfers that was found to be very relevant for primary purpose event visitors from Germany in the current study should also hold true for potential primary purpose event visitors from other countries. This means that surfers that are popular in other markets should be used in the event communication targeted at foreign visitors.

In terms of destination marketing, we have seen that the primary purpose event visitors averaged rather low scores on almost all leisure motivation dimensions. Yet, "learning about the destination" scored slightly above the average value of 3.5, and "to discover new things about Sylt" was the highest rated item after the two vicarious achievement items and the one relating to cheering for the surfers. This leads to the conclusion that a considerable number of the respondents in this group were interested in the destination. Since the other leisure-related dimensions are not necessarily related to the destination, this is a rather positive message for Sylt. Even though the scores here are not very high, the notion that such an event can help to popularise the destination where it is staged has, at the very least, not been contradicted. For the marketing of the event, the conclusion can be drawn that destination-related marketing efforts could be more fruitful than emphasising the entertainment experience or the aesthetics of windsurfing (see tab. 3 and tab. 4).

The casual visitors who are not on the island exclusively for the event, scored considerably - and significantly - higher on leisure motivation than the primary purpose event visitors. They also scored higher on fan motivation by almost twice the margin. In total, the casual visitors' fan motivation outscored their leisure motivation, which may seem counterintuitive at first sight. Yet, this observation is rather logical when a look is taken at the words that introduce the different items measuring motivation in the questionnaire (tab. 1). All items were listed after the following introduction: "One of the reasons for attending the Reno Windsurf World Cup is.... Consequently, casual visitors should have rated some of the leisure motivation items comparably low. For instance, if a respondent did not consider the event an opportunity "to discover new things about Sylt", he would not score this item high, even though his holiday trip might have been motivated by a desire to get to know the island better. The same is true of the escape dimension. Even though the holiday trip itself may have been motivated by items in this category, the actual visit to the World Cup might not have.

It turned out that "entertainment experience" and "vicarious achievement" were the most dominant motivational dimensions for the casual visitors, which indicates that marketing efforts geared towards this group could utilise similar strategies as the ones for primary purpose visitors. It further shows that the event seems to be a very attractive element of staying on the island. Since the event visitors on Sylt usually seem to plan their trip well in advance and the Windsurf World Cup is prominently included in the marketing efforts of the official Sylt marketing organisation, it can be expected that most of the casual visitors knew that they would have the opportunity to go to the event. Regarding this specific destination-event combination, it can thus be concluded that many casual visitors planned their trip at least with some relation to the World Cup. Consequently, it would be very interesting to inquire if such an event constitutes a major motivator to visit the destination for potential casual visitors in future studies.

Although the study has delivered interesting results, some methodological limitations have to be addressed. As could be seen, the questionnaire that had been adapted from Snelgrove et al. [7] mostly yielded solid results. But the average values of the items in the "entertainment experience" dimension varied greatly (between 2.50 and 4.22 for the primary purpose group 
and between 3.11 and 4.99 for the casual group). This was mainly so because the item "the main reason I watch windsurfing is to cheer for my favourite surfers" received very high average scores from both groups. Consequently, one might wonder whether the alteration of the original item from Snelgrove et al.'s survey ("to see future stars of Athletics") should have been conducted differently. On a content level, our alteration can be seen as suitable because the new item is very closely linked to vicarious achievement, which was the highest scoring dimension for both groups. However, even without this item, there was a rather large margin between two of the remaining ones in the entertainment experience dimension, because "to watch high level windsurfing" scored 0.9 lower than "I like the stimulation I get from watching windsurfing" for both groups. Consequently, it can be concluded that even though the motivational structure of sport event visitors at a mature tourist destination was analysed insightfully, some room for improvement is left to be filled by future projects.

Another opportunity for methodological improvement could be an alteration of the question that was used to separate primary purpose event visitors and casual visitors. The question was: "Did you come to Sylt ONLY because of the Reno Windsurf World Cup?" It would be insightful to obtain more detailed information here to allow for a more detailed segmentation of the event visitors. It would, for instance, be very interesting to differentiate between "actual" casual visitors, that is event visitors who did not include the event in their holiday plans prior to the trip to the island, and casual visitors who did. The latter group could be asked if they would not have planned a vacation on the island if the World Cup were not taking place or if they would have visited it at another time. This information cannot be drawn from the current data set. It would also be useful to expand the analysis of the event visitors' motives to get an overall picture of their motivation to come to the island. Thus, it could be determined which leisure motives are important concerning the destination itself.

Concluding this paper, it can be stated that Scott was right when he recommended "that more comparative studies be pursued [...] as a predictor of people's motivations" [32]. These studies have the capacity to shed considerable light on (sport) event visitors' motivations that can help (sport) event and destination managers and marketers alike to improve their customers' experience by getting to know them better. Consequently, scholars should be motivated to conduct further studies in other environments to widen the knowledge on parallels and differences in the motivational setup of different types of sport event visitors and sport tourists.

\section{Literature}

1. Kim N.-S., Chalip L. (2004). Why travel to the FIFA World Cup? Effects of motives, background, interest, and constraints. Tourism Management 25(6), 695-707.

2. Tkaczynski A., Rundle-Thiele S.R. (2011). Event segmentation: A review and research agenda. Tourism Management 32(2), 426-434.

3. Schneider U. (1993). City marketing and major events. Beiträge zur angewandten Wirtschaftsforschung Vol. 26. Berlin: Duncker und Humblot. [in German]

4. Beard J.G., Ragheb M.G. (1983). Measuring leisure motivation. Journal of Leisure Research 15(3), 219-228.
5. Wann D.L. (1995). Preliminary validation of the sport fan motivation scale. Journal of Sport E Social Issues 19(4), 377396.

6. Wann D.L., Melnick M.J., Russell G.W., Pease D.G. (2001). Sport fans: The psychology and social impact of spectators. New York: Routledge. Retrieved March 1, 2016, from http:// www.loc.gov/catdir/enhancements/fy0651/00032821-d. html.

7. Snelgrove R., Taks M., Chalip L., Green B.C. (2008). How visitors and locals at a sport event differ in motives and identity. Journal of Sport E Tourism 13(3), 165-180.

8. Preuss H. (2005). The economic impact of visitors at major multi-sport events. European Sport Management Quarterly 5(3), 281-301.

9. Könecke T., Preuß H., Schütte N. (2015). Direct regional economic impact of Germany's 1. FC Kaiserslautern through participation in the 1. Bundesliga. Soccer \& Society Online first version. Retrieved March 1, 2016, from http:// www.tandfonline.com/doi/full/10.1080/14660970.2015. 1067786. DOI: 10.1080/14660970.2015.1067786.

10. Kwiatkowski G. (2016). Composition of sport event attendees - A comparison of three non-mega events. International Journal of Sport Finance 11(2), 163-180.

11. Kwiatkowski G. (2016). Economic impact of event attendees' primary spending on a host region: A review of the research. Event Management 20(3), in press.

12. Green C.B. (2001). Leveraging subculture and identity to promote sport events. Sport Management Review 4(1), 1-19.

13. Daniels M.J., Norman W.C. (2005). Motivations of equestrian tourists: An analysis of the colonial cup races. Journal of Sport \& Tourism 10(3), 201-210.

14. Cohen S.A., Prayag G., Moital M. (2014). Consumer behaviour in tourism: Concepts, influences and opportunities. Current Issues in Tourism 17(10), 872-909. DOI: 10.1080/13683500.2013.850064.

15. McCabe A.S. (2000). Tourism motivation process. Annals of Tourism Research 27(4), 1049-1052.

16. Quinn K.G. (2009). Sports and their fans: The history, economics, and culture of the relationship between spectator and sport. Jefferson: McFarland.

17. Yu C.-C. (2010). Factors that influence international fans' intention to travel to the United States for sport tourism. Journal of Sport E Tourism 15(2), 111-137.

18. Gnoth J. (1997). Tourism motivation and expectation formation. Annals of Tourism Research 24(2), 283-304. DOI: 10.1016/S0160-7383(97)80002-3.

19. Nicholson R.E., Pearce D.G. (2001). Why do people attend events: A comparative analysis of visitor motivations at four south island events. Journal of Travel Research 39(4), 449460. DOI: 10.1177/004728750103900412.

20. Yoo I.Y., Lee T.J., Lee C.-K. (2013). Effect of health and wellness values on festival visit motivation. Asia $\mathrm{Pa}$ cific Journal of Tourism Research 20(2), 152-170. DOI: 10.1080/10941665.2013.866970.

21. Gibson H.J., Kaplanidou K., Kang S.J. (2012). Small-scale event sport tourism: A case study in sustainable tourism. Sport Management Review 15(2), 160-170.

22. Agha N., Taks M. (2015). A theoretical comparison of the economic impact of large and small events. International Journal of Sport Finance 10(3), 199-216.

23. Diedering M., Kwiatkowski G. (2015). Economic impact of events and festivals on host regions - methods in practice and potential sources of bias. Polish Journal of Sport and Tourism 22(4), 241-246. 
24. Kwiatkowski G., Oklevik O. (2017). Primary economic impact of small-scale sports events. Event Management 21(2), in press.

25. ACT Agency GmbH. (2013). World Cup stories. History and stories from over 25 years of World Cup on Sylt. Retrieved March 1, 2016, from https://web.archive.org/ web/20131020042727/http://www.windsurfworldcup.de/ event/event-history/world-cup-geschichten/. [in German]

26. Insel Sylt Tourismus-Service GmbH. (2014). Event Guide: 26.09.-05.10.2014 Westerland. Retrieved March 1, 2016, from http://issuu.com/terraoceanisverlag/docs/ wwcs_2014_web-pdf.

27. Steinhardt S. (2014). Windsurf World Cup on Sylt: Elite sport and party. Retrieved March 1, 2016, from http://www.ndr. de/nachrichten/schleswig-holstein/Windsurf-WorldcupSylt-Party-und-Spitzensport,surfen206.html. [in German]

28. Sylt Marketing GmbH. (2013). Press portfolio Sylt: Sea. Passion. Life. Retrieved March 1, 2016, from http://www.sylt. de/fileadmin/Mediendatenbank/PDFs/Download/SMG/ Berichte/Pressemappe_2.0.pdf. [in German]
29. Lohr S.L. (2010). Sampling: Design and analysis (2 ${ }^{\text {nd }}$ ed.). Boston, USA: Books/Cole.

30. Preuß H., Kurscheidt M., Schütte N. (2009). Economics of tourism through sporting events: An Empirical Analysis for the 2006 FIFA World Cup. Gabler Research: Event and impact research. Wiesbaden: Gabler. [in German]

31. Adelson J.L., McCoach D.B. (2010). Measuring the mathematical attitudes of elementary students: The effects of a 4-point or 5-point Likert-Type Scale. Educational and Psychological Measurement 70(5), 796-807.

32. Bartlett J.E., Kotrlik J.W., Higgins C.C. (2001). Organizational research: Determining appropriate sample size in survey research. Information Technology, Learning and Performance Journal 19(1), 43-50.

33. Scott D. (1996). A comparison of visitors' motivations to attend three urban festivals. Festival Management and Event Tourism 3(3), 121-128.

Submitted: April 14, 2016

Accepted: May 31, 2016 